\title{
Copa do mundo de futebol 2014: análise do impacto da receita e volume de vendas do comércio, dos serviços e da produção industrial nos estados brasileiros
}

Tatiane Salete Mattei

Mestranda pelo Programa de Pós Praduação Stricto Sensu em Gestão e Desenvolvimento Regional com linha de pesquisa Desenvolvimento Regional e Agroindústria pela Universidade Estadual do Oeste do Paraná- UNIOESTE Campus Francisco Beltrão, Paraná, Brasil. Graduada em Ciências Econômicas pela Universidade Estadual do Oeste do Paraná- UNIOESTE Campus Francisco Beltrão, Paraná, Brasil.

tati_mattei@hotmail.com

Gilmar Ribeiro de Mello

Doutor e Mestre em Ciências Contábeis pela Universidade de São Paulo - FEA/USP; Bacharel em Ciências Contábeis pelo Centro Federal de Educação Tecnológica do Paraná. Professor Adjunto da Universidade Estadual do Oeste do Paraná - Unioeste, atuando no Mestrado em Gestão e Desenvolvimento Regional (Campus de Francisco Beltrão, Paraná, Brasil), Paraná, Brasil gilmarribeirodemello@gmail.com

\section{Editor Científico: José Edson Lara}

Organização Comitê Científico

Double Blind Review pelo SEER/OJS

Recebido em 23.09.2016

Aprovado em 12.04.2017

Este trabalho foi licenciado com uma Licença Creative Commons - Atribuição - Não Comercial 3.0 Brasil
} 


\title{
Resumo
}

O estudo utiliza dados secundários do IBGE com objetivo de verificar se a Copa do Mundo de Futebol 2014 impactou significativamente no volume de vendas e receita nominal do comércio varejista, na receita de serviços e na produção industrial nos estados brasileiros que foram e os que não foram sede dos jogos. Para isso foi preciso verificar o comportamento dessas variáveis no período de realização (junho/julho 2014) e nos 20 meses e 3 meses anteriores e posteriores ao evento utilizando os testes $\mathrm{T}$ e Wilcoxon com auxílio do software estatístico SPSS. Na comparação das variáveis nos períodos anteriores e posteriores não se verificaram grandes diferenças nos estados sede para os que não foram sede da Copa. Com poucas exceções conclui-se que nos dois meses de realização do evento os valores da receita e volume de vendas do comércio varejista, receita de serviços e produção industrial se apresentaram menores comparados aos dois meses anteriores e posteriores.

Palavras-chave: Indústria. Comércio. Serviços. Copa do Mundo.

\section{World Cup 2014: Analysis of the Impact of Revenue and Sales Volume of Commerce, Services and Industrial Production in the Brazilian States}

\begin{abstract}
The study uses secondary data from the Brazilian Institute of Geography and Statistics (IBGE) in order to verify if the 2014 Soccer World Cup had a significant impact on the sales volume and nominal revenue of retail trade, services revenue and industrial production in the Brazilian states that were and were not Headquarters of the games. For this, it was necessary to verify the behavior of these variables in the period of performance (June / July 2014) and in the 20 months and 3 months before and after the event using the $T$ and Wilcoxon tests with the help of the statistical software SPSS. In the comparison of the variables in the previous and subsequent periods, there were no major differences in the host states for those who did not host the World Cup. With few exceptions, it can be concluded that in the two months of the event, sales revenue and sales volume of retail trade, service revenue and industrial production were lower compared to the two previous and subsequent months.
\end{abstract}

Key-words: Industry. Trade. Services. World Cup. 
Análisis de impacto en los ingresos y volumen de ventas de Comercio, Servicios y Producción industrial en el brasileño: Copa Mundial de Fútbol 2014

\section{Resumen}

El estudio utiliza datos de IBGE secundaria con el fin de verificar que la Copa Mundial de Fútbol en 2014 afectó significativamente el volumen de ventas y el ingreso nominal de comercio al por menor en los ingresos por servicios y la producción industrial en los estados brasileños que tienen y los que no tienen sede de los juegos. Para esto era necesario para verificar el comportamiento de estas variables en el período de aplicación (junio / julio de 2014) y 20 meses y 3 meses antes y después del evento mediante pruebas t de Wilcoxon y con la ayuda del software SPSS. En la comparación de las variables en los períodos antes y después no hubo diferencias importantes en las oficinas centrales del estado para los que no anfitrión de la Copa Mundial. Con pocas excepciones, se concluye que el plazo de dos meses desde la finalización de la receta valores de eventos y el volumen de ventas al por menor, los ingresos de los servicios y la producción industrial mostró menor en comparación con los dos meses anteriores y posteriores.

Palabras clave: Industria. Comercio. Servicios. Copa del Mundo.

\section{Introdução}

A Copa do Mundo de Futebol 2014 aconteceu no Brasil, entre junho e julho, em meio a protestos, greves e discussões a favor e contra sua realização. Muitos afirmavam que o evento traria benefícios e outros apontavam apenas os transtornos que o evento causaria. Instigado por algumas notícias vinculadas na mídia após a Copa do Mundo onde alguns comerciantes não ficaram satisfeitos com as vendas durante o evento e outras notícias informando o saldo positivo para os negócios, que o presente trabalho foi idealizado com o objetivo de verificar o real impacto no volume de vendas e receita nominal do comércio varejista, na receita de serviços e na produção industrial.

Segundo inferências de alguns autores como Mankiw (2001) e Krugman e Wells (2007), o comércio nos infere que comercializando com outros, as pessoas compram uma variedade maior de bens e serviços a um custo menor, visto que ele permite que as pessoas se especializem nas atividades que são mais habilidosas Comércio é a chave para um padrão de vida melhor, o meio em que as pessoas 
dividem as tarefas entre si, cada um oferece um bem ou serviço que outras pessoas desejam em troca de bens e serviços diferentes.

Em países subdesenvolvidos como o Brasil o setor de serviços se apresenta de um lado moderno e organizado, conectado a indústria produtiva, e de outro um setor que absorve mão de obra excedente, de baixa produtividade, e também pessoas excluídas do mercado formal. Apesar dessas visões, o setor vem sendo considerado elemento dinâmico da economia, com crescente participação no produto e no emprego principalmente pelos serviços que são empregados durante o processo produtivo em empresas e os serviços pessoais, destinados aos consumidores finais, fascinados pelo consumismo em massa (Diniz, 2007).

As indústrias são consideradas o foco estratégico daqueles países que desejam superar a situação de dependência econômica. Por meio das indústrias é possível uma produção com maior valor agregado, progresso técnico, melhor inserção no cenário internacional, tudo isso contribuindo para o desenvolvimento (Gadelha, 2006).

O trabalho se justifica pela importância que o comércio, indústria e serviços desempenham em uma economia como geradores de valor, gerador de empregos e distribuição de renda. Os setores se interligam, a famílias possuem necessidades ilimitadas de bens e serviços e encontram seus produtos no mercado porque empresas estão dispostas a produzir bens e serviços e comercializá-los para obter lucros. As empresas para a produção de bens e serviços necessitam dos fatores de produção que encontram nas famílias, como exemplo a mão de obra (Passos \& Nogami, 1998).

Tudo o que é comercializado precisa antes ser produzido, é em virtude do comércio que pessoas, empresas, países se concentram naquilo que produzem melhor, é o que Ricardo chamou de vantagem comparativa (Stiglitz \& Walsh, 2003). Nessa perspectiva surge a problemática: a receita e volume de vendas do comércio varejista, receitas de serviços e produção industrial foram impactados significativamente pela realização da Copa do Mundo de Futebol 2014?

O objetivo principal é analisar se o evento Copa do Mundo de Futebol 2014 impactou de forma significativa no volume de vendas e receita nominal do comércio varejista, receita de serviços e produção industrial nos estados brasileiros que foram sede e os que não foram sede dos jogos. Para isso foi preciso verificar o 
comportamento dessas variáveis no período de realização do evento e nos 20 meses e 3 meses antes e depois da Copa do Mundo.

O artigo está estruturado da seguinte forma: na primeira seção apresenta-se a introdução com objetivo e justificativas. Na segunda seção está o Referencial Teórico com tópicos sobre comércio e serviços, produção industrial, Copa do Mundo no Brasil e uma breve explicação sobre as pesquisas mensais do IBGE. Na terceira seção é apresentada a metodologia utilizada, na quarta seção os resultados, na quinta as considerações finais e por fim as referências utilizadas.

\section{Referencial Teórico}

Em uma economia existem elos entre os agentes econômicos - famílias, empresas e governo. As empresas produzem bens e serviços para venda, para isso precisam transformar vários insumos (fatores de produção) como terra, capital e trabalho em produtos. A quantidade de produtos que uma empresa produz depende da quantidade de insumos, essa relação é a função de produção (Krugman \& Wells, 2007).

As empresas empregam membros das famílias que são os proprietários dos fatores de produção, as famílias recebem renda e a compartilham em troca de outros bens e serviços. Empresas e famílias usam parte de sua renda para pagar impostos ao governo. O governo com a receita dos impostos emprega membros das famílias e paga suas despesas com bens e serviços (Krugman \& Wells, 2007; Mankiw, 2001).

\subsection{Comércio e serviços}

O comércio, função urbana onde são trocadas mercadorias, tem sua origem ligada à história da humanidade. Surgiu a partir do momento em que a produção ultrapassou o necessário para sobrevivência, ou seja, foi a produção de excedente que permitiu o intercâmbio. $O$ aperfeiçoamento dos meios de produção, principalmente pelo aprimoramento das técnicas aumentou a produção e em consequência a atividade comercial se intensificou (Cleps, 2004; Freire, 2010).

Segundo Krugman e Wells (2007), o comércio é a chave para um padrão de vida melhor, ele é o meio em que as pessoas dividem as tarefas entre si, cada um 
oferece um bem ou serviço que outras pessoas desejam em troca de bens e serviços diferentes. Dessa divisão de tarefas surge a especialização. Quando os indivíduos se especializam a economia produz mais. Graças aos mercados é possível que as pessoas se especializem e troquem seus bens e serviços.

$\mathrm{Na}$ Inglaterra, por volta de 1750, já se verificava o desaparecimento dos camponeses diante das grandes propriedades agrícolas. No início do século XVIII, com a modernização da agricultura, as famílias que viviam nas zonas rurais migravam para as cidades com apenas uma solução, vender sua força de trabalho, em troca de baixos salários, nos grandes centros industriais que se multiplicavam em ritmo acelerado. A Revolução Industrial transformou as regras do trabalho e convívio social e possibilitou transformações econômicas e sociais. Os lucros altíssimos foram a base da formação da sociedade industrial (Freire, 2010; Scandelai, 2010; Ugarte, 2004).

De acordo com Diniz (2007) o setor de serviços é caracterizado pela não produção de bens materiais, pela intangibilidade, inestocabilidade e simultaneidade entre produção e consumo. Pode-se verificar nos países subdesenvolvidos, como o Brasil, de um lado o setor de serviços moderno e organizado conectado a indústria produtiva e de outro um setor que absorve mão-de-obra excedente de baixa produtividade e também pessoas excluídas do mercado formal. Apesar dessas visões o setor vem sendo considerado elemento dinâmico da economia, com crescente participação no produto e no emprego principalmente pelos serviços que são empregados durante o processo produtivo em empresas. Tem destaque também os serviços pessoais, destinados aos consumidores finais, fascinados pelo consumismo em massa muito ligados às inovaçõe.

Kureski e Delgado (2012) enfatizam que a atividade de serviços é importante, e a partir de 1970 tem possibilitado uma nova estruturação com a emergência de empresas transnacionais de serviços, criação de novas funções ocupacionais e ligação dos serviços como elemento de agregação de valor aos produtos industriais. Algumas atividades ligadas aos serviços, particularmente ligados a tecnologia de informação e comunicação, constituem importante vetor de inovação e crescimento econômico para os países. Os setores de serviços de saúde e educação constituem o sistema de proteção social dos países.

A dinâmica econômica dos países no longo prazo é um processo de transformação estrutural onde a geração de renda e emprego se inicia na $\Theta$ Revista Gestão \& Tecnologia, Pedro Leopoldo, v. 17, n. 1, p. 207-231, jan./abr. 2017212 
agricultura, se deslocando para a indústria passando pelo setor de comércio e serviços $^{1}$ (Carvalho, 2004; Kureski \& Delgado, 2012).

Durante muitos anos ocorreu grande debate na literatura sobre o caráter produtivo ou improdutivo dos setores do comércio e serviços. Atualmente não se tem dúvidas que esses setores, juntamente com o setor industrial, são a base de uma economia, gerador e distribuidor de renda e gerador de empregos, além de serem setores que se interligam (Carvalho, 2004).

Para demonstrar essa ligação, Mariano (2007) enfatiza que a atividade comercial está na ponta do ciclo de produção de mercadorias e é sensível as variações conjunturais. As novas tecnologias e os novos processos produtivos podem alterar a utilização de mão-de-obra nas atividades industriais. É crescente a participação do setor de comércio e serviços tanto nos países desenvolvidos quando nos países periféricos. A tendência é que se reduza cada vez mais o número de pessoas envolvidas durante a produção de bens e mais pessoas envolvidas nas atividades comerciais.

\subsection{Produção Industrial}

A produção é a base do sistema econômico de um país, o desenvolvimento é alcançado por uma nação se for alcançado a eficiência do sistema produtivo, transformando materiais, energia e trabalho em produtos tangíveis e intangíveis por meio de processos produtivos e tecnológicos (Paranhos Filho, 2007).

Para satisfazer as necessidades ilimitadas que possui, o homem envolve-se no ato de produção, "atividade social que visa adaptar a natureza para criação de bens e serviços que permitem a satisfação das necessidades humanas" (Gremand, Vasconcellos \& Toneto Junior, 2007, p. 54). Os indivíduos para obterem o que necessitam devem trocar seus produtos no mercado por moeda e comprar os outros bens de que necessitam. A produção é a principal atividade econômica a ser medida

\footnotetext{
${ }^{1}$ Nas contas nacionais e no sistema de classificação da Organização das Nações Unidas (ONU) o comércio está incluído entre as atividades de serviços. Existe uma classificação global em que o setor primário engloba as atividades agrícolas, de caça, pesca e extrativismo. O setor secundário engloba as manufaturas e o setor terciário as demais atividades. No presente trabalho comércio e serviços serão analisados como dois setores distintos.
} 
pois reflete a capacidade de satisfação das necessidades dos membros da sociedade.

A industrialização é sinonimo de desenvolvimento e países industrializados apresentam também maiores rendas per capita, e melhor condição de vida da população como saúde, educação e infra estrutura por exemplo (Paranhos Filho, 2007).

Neste sentido Gadelha (2006) cita que as indústrias são consideradas o foco estratégico daqueles países que desejam superar a situação de dependência econômica. Por meio das indústrias é possível uma produção com maior valor agregado, progresso técnico, melhor inserção no cenário internacional, tudo isso contribuindo para o desenvolvimento. No nível político a indústria possibilitaria uma aliança entre a burguesia industrial e os trabalhadores, em detrimento aos segmentos primário-exportadores tidos como atrasados. Em síntese a luta pelo desenvolvimento é a luta pela industrialização.

A década de 1930 é marcada pela estagnação e declínio da produção cafeeirae inicio do processo de industrialização no Brasil, através de um processo chamado de substituição de importações. A industrializão teve por característica ser fechada, ou seja, voltada para o mercado interno não para exportação e depedente de protecionismo (Deitos, 2012; Gremand, Vasconcellos \& Toneto Junior, 2007).

A industrialização acelerada do Brasil entrou na agenda política entre o pósguerra e o final dos anos 1970 e foi impulsionada por políticas industriais, fortaleceram-se nessa época diversos atores políticos: associações industriais, sindicatos patronais e de trabalhadores, órgãos regionais e setoriais (Suzigan \& Furtado, 2006).

\subsection{Brasil e a Copa do Mundo de Futebol}

Em outubro de 2007 ocorreu o sorteio pela Federation Internationale de Football Association (FIFA) que escolheu o Brasil para ser sede da Copa do Mundo de Futebol 2014. Em meados de 2009 foram escolhidas as 12 cidades que foram sede dos jogos, evento que ocorreu entre 12 de junho e 13 de julho de 2014 (Domingues, Bertarelli Junior \& Magalhães, 2011; Glória Junior, 2015).

Foi gerada, principalmente influenciada pelos meios de comunicações, uma grande expectativa e também discussões positivas e pessimistas a respeito da 
realização do evento, especialmente na questão dos benefícios econômicos que o evento traria para o país, os gastos com as obras de infraestrutura urbana, reformas/construção de estádios, além dos fluxos turísticos (Domingues et al., 2011; Ribeiro, Soares \& Dacosta, 2014; Glória Junior, 2015).

Pace, Hardt e Figueiredo (2015) citam em seu estudo que grandes eventos promovem alterações no ambiente cultural, político, social e econômico. São projetadas para promover resultados positivos como a criação de infraestrutura necessária, porém ao mesmo tempo surgem conflitos, pois dificilmente as receitas vão cobrir os custos no curto prazo. As consequências podem se estender para a fase pós-evento, principalmente em longo prazo para o turismo, para a indústria e para a entrada de capital financeiro. Esses eventos desencadeiam também outros fatores positivos, como aumento do número de visitantes, aumento da visibilidade e possibilidades de comercialização que catalisam negócios, melhoria na segurança e transporte.

Bayar e Schaur (2014) enfatizam que eventos como a Copa do Mundo proporcionam impactos positivos sobre o comércio, principalmente no quesito visibilidade aumentando as exportações temporariamente em $5 \%$, pois o evento é acompanhado por pessoas de toda parte do mundo.

Porto e Ceron (2013) afirmavam que a Copa do Mundo traria inúmeros benefícios econômicos, que a economia iria deslanchar como uma bola de neve, onde os investimentos iriam quintuplicar e gerar um impacto em diversos setores do país, principalmente gerando empregos. Glória Junior (2015) enfatiza que esse tipo de evento esportivo representa uma ferramenta de comunicação mais promissora da atualidade e que as promoções e propagandas de vendas são direcionadas de forma consistente ao público interessado no evento.

Conforme Portal da Copa no site do Governo Federal Brasileiro sobre a Copa do Mundo FIFA 2014 (http://www.copa2014.gov.br/pt-br/noticia/governo-federal-fifae-cbf-apresentam-legados-da-copa-do-mundo-de-2014, recuperado em 16, junho, 2016), a Copa das Confederações adicionou $R \$ 9,7$ bilhões ao PIB brasileiro, e a expectativa era que a Copa do Mundo gerasse cerca de 3 vezes mais. Esperava-se que os setores que mais contribuíssem para o resultado seriam a construção civil, turismo, serviços, economia criativa, artesanato, alimentos, confecção e comércio varejista tendo em vista o grande número de turistas no país. 
Não foi encontrada pesquisa exatamente com o mesmo objetivo que o presente trabalho, onde utilizassem dados fornecidos pelo IBGE de indústria, comércio e serviços para verificar se a Copa do Mundo influenciou nessas atividades. Domingues, Bertarelli Junior e Magalhães (2011) apresentam um estudo no sentido econômico onde verificaram os impactos dos investimentos em infraestrutura urbana e esportiva para a Copa do Mundo 2014 no Brasil e concluiram que quanto maior a utilização de recursos públicos no financiamento dos investimentos da Copa 2014, menor seu impacto econômico.

Se verifica nos noticiários no Portal da Copa no site do Governo Federal Brasileiro sobre a Copa do Mundo FIFA 2014 (http://www.copa2014.gov.br/pt$\mathrm{br} /$ noticia/governo-federal-fifa-e-cbf-apresentam-legados-da-copa-do-mundo-de2014, recuperado em 16, junho, 2016), que o legado da Copa foi positivo, não só para o bem estar da população, mas também para o desenvolvimento. Um exemplo foi na cidade de Porto Alegre, onde a demanda do comércio, bares, restaurantes e similares, tiveram um aumento de cerca de $50 \%$, os serviços de turismo aumentaram $40 \%$ e a rede hoteleira verificou uma ocupação média de $80 \%$.

Em contrapartida, outros noticiários no portal UOL em Notícias sobre a Copa do Mundo (http://copadomundo.uol.com.br/noticias/redacao/2014/06/27/copa-domundo-decepciona-comercio-e-restaurantes-setor-preve-perda-no-rio.htm, recuperado em 16, junho, 2016) informam que comerciantes, principalmente do Rio de Janeiro, não ficaram satisfeitos com a Copa do Mundo, alegando não obtenção de lucros. Estes informaram que os feriados atrapalharam o movimento e apenas aqueles estabelecimentos localizados ao redor dos estádios verificaram aumento expressivo nas vendas.

\subsection{Pesquisas mensais do IBGE}

O Instituto Brasileiro de Geografia e Estatística (IBGE) divulga mensalmente a Pesquisa Mensal de Comércio, a Pesquisa Mensal de Serviços e a Pesquisa Industrial Mensal, cujos indicadores fornecem dados do comportamento conjuntural desses setores no Brasil, esses indicadores foram a base de dados da pesquisa (Intituto Brasileiro de Geogradia e Estatística [IBGE], 2016).

A Pesquisa Mensal de Comércio (PMC) pesquisa atualmente 5.700 empresas distribuídas nas 27 Unidades da Federação que possuem 20 ou mais pessoas 
ocupadas. Essas empresas são classificadas em 10 grupos, com base na Classificação Nacional de Atividades Econômicas (CNAE), cuja atividade principal é o comércio varejista, sendo que apenas dois grupos são do atacado e varejo (IBGE, 2016).

Para o comércio são fornecidos dois indicadores: Receita Nominal de Vendas e Volume de Vendas. Neste trabalho foram considerados os indicadores ampliados, onde abrange os 10 grupos. Para os anos estudados nessa pesquisa os valores são deflacionados basicamente com base no IPCA de 2011 (IBGE, 2016).

A Pesquisa Mensal de Serviços (PMS) investiga a receita bruta de serviços de 9.300 empresas, distribuídas nas 27 Unidades da Federação, constituídas por 20 ou mais pessoas ocupadas, cuja receita provenha predominantemente da atividade de prestação de serviços. A PMS abrange 5 grupos de atividades empresariais nãofinanceiras e seus principais segmentos classificados pela CNAE, excluídas as áreas de saúde e educação (IBGE, 2016).

A Pesquisa Industrial Mensal (PIM) investiga a produção física das indústrias, mas não abrange os seguintes estados: Rondônia, Acre, Roraima, Amapá, Tocantins, Maranhão, Piauí, Rio Grande do Norte, Paraíba, Alagoas, Sergipe, Mato Grosso do Sul, Mato Grosso e Goiás. O critério de seleção dos estados foram os que responderam por pelo menos $1,0 \%$ do Valor da Transformação Industrial, tomando-se como referência o resultado da PIA-Empresa 2010, além da Região Nordeste (IBGE, 2016).

\section{Metodologia}

O presente trabalho teve natureza descritiva com procedimento bibliográfico e abordagem quantitativa. Utilizou testes estatísticos de hipóteses para comparar duas médias emparelhadas. Foram feitas comparações das médias no período do evento, em períodos anteriores e posteriores à Copa do Mundo para os estados que foram sede e os que não foram sede dos jogos.

As variáveis utilizadas para o setor comercial foram os indicadores fornecidos pelo IBGE através da PMC, índices de volume de vendas ampliado e índices de receita nominal ampliado. Para o setor de serviços foi utilizado os índices de receita nominal de serviços fornecido pelo IBGE através da PMS. Para o setor industrial foi utilizado os Indicadores da Produção Industrial retirado do IBGE através da PIM. 
O período de realização do evento foi junho e julho de 2014. A análise foi feita comparando os 20 meses anteriores ao evento (outubro/2012 a maio/2014) com os 20 meses depois da Copa (agosto/2014 a março/2016), período máximo de dados que se tem disponível publicado pelo IBGE para os meses posteriores ao evento. Outra análise foi feita comparando os 3 meses anteriores (março, abril e maio/2014) com os 3 meses posteriores à Copa (agosto, setembro e outubro/2014) para verificar como estava o cenário no período imediato de preparação para o evento, nesse período se supõe que os setores comércio, serviço e indústria estivessem mais aquecidos em decorrência da Copa.

Para verificar a influência da Copa do Mundo na receita e volume de vendas do comércio varejista, receita de serviços e produção industrial nos meses de realização do evendo, foi utilizada a média dos indicadores dos dois meses anteriores a Copa (abril e maio/2014) comparando-os com a média dos dois meses de duração da Copa (junho e julho/2014), e a média dos indicadores do período de realização do evento com a média dos dois meses posteriores (agosto e setembro/2014).

A população do estudo são os 27 estados brasileiros mais o Distrito Federal. Como nem todos os estados brasileiros tiveram jogos da Copa do Mundo de Futebol a amostra foi dividida nos 12 estados que foram sede da Copa e nos 15 estados que não foram, para a análise do comércio e serviços, conforme Quadro 1.

\begin{tabular}{|c|c|}
\hline ESTADOS SEDE COPA & ESTADOS SEM COPA \\
\hline Amazonas & Rondônia \\
\hline Ceará & Acre \\
\hline Rio Grande do Norte & Roraima \\
\hline Pernambuco & Pará \\
\hline Bahia & Amapá \\
\hline Minas Gerais & Tocantins \\
\hline Rio de Janeiro & Maranhão \\
\hline São Paulo & Piauí \\
\hline Paraná & Paraíba \\
\hline Rio Grande do Sul & Alagoas \\
\hline Mato Grosso & Sergipe \\
\hline Distrito Federal & Espírito Santo \\
\hline & Santa Catarina \\
\hline & Mato Grosso do Sul \\
\hline & Goiás \\
\hline
\end{tabular}

\section{Quadro 1}

Estados brasileiros considerados na análise do comércio e serviços.

Fonte: Domingues, E. P., Betarelli Junior, A. A., Magalhães, A. S. (2011). Quanto vale o show? Impactos econômicos dos investimentos da Copa do Mundo 2014 no Brasil. Estudos Econômicos 41(2), pp. 409-439. 
Para a análise do setor industrial a amostra foi ainda mais reduzida em virtude de não divulgação dos dados pelo IBGE. Para os estados sede da Copa do Mundo de Futebol foram retirados Mato Grosso e Distrito Federa totalizando 10 estados. Para os estados que não foram sede dos jogos foram considerados apenas 4 estados são eles: Pará, Espirito Santo, Santa Catarina, Goiás.

O teste $t$ é aplicado para verificar se as médias de duas amostras relacionadas com distribuição normal são ou não significativamente diferentes. O teste exige a normalidade dos dados de cada amostra e que as variâncias sejam iguais. Se verificou a normalidade pelo teste de Shapiro-Wilk, mais indicado para pequenas amostras (<30) (Fávero, Belfiore, Silva \& Chan ,2009).

Para a comparação das médias das amostras com distribuição normal foi aplicado o teste de Levene para cumprir a exigência da homogeneidade das variâncias e dando significativo foi aplicado o teste paramétrico t. Em todo o trabalho foi utilizado nível de confiança de 95\% e nível de significância para aceitação das hipóteses de 5\%, ou seja, Sig. ou p-value de 0,05.

Para aquelas amostras que não apresentaram distribuição normal ou não foram significativos no Levene foi utilizado o teste de Wilcoxon para a comparação das médias. Esse teste é uma alternativa ao teste t de Student e uma extensão do teste dos sinais. Além da informação sobre a direção das diferenças para cada par, o teste de Wilcoxon leva em consideração a magnitude da diferença entre os pares e os Ranks das médias. Esse ranqueamento que o teste oferece, foi importante para a análise, por isso foi feito esse teste para todas as amostras, mesmo daquelas em que foi utilizado o teste t para comparar as médias (Fávero et al., 2009).

O primeiro passo dos testes é estabelecer a hipótese a ser testada, chamada de hipótese nula, posteriormente deve-se estabelecer a hipótese alternativa para ser usada, caso a hipótese nula seja rejeitada foram (Fávero et al., 2009).

As hipóteses dos testes são: $H_{0}=$ as médias são iguais, ou seja, não há diferenças; $\mathrm{H}_{1}=$ as médias são diferentes. Quando não rejeitar $\mathrm{H}_{0}$ a conclusão será que as médias são iguais, ou seja, não teve alteração na receita e volume de vendas, receita de serviços e produção industrial nos períodos estudados. Quando se rejeitar $H_{0}$ a conclusão será que houveram diferenças nos indicadores de comércio, indústria e serviços. 
Os testes estatísticos foram realizados com o auxilio do programa Statistical Package for Social Sciences (SPSS) versão 18.

\section{Apresentação e Análise dos Resultados}

Inicialmente os dados passaram pela análise de normalidade por meio do teste paramétrico de Shapiro-Wilk, os dados que apresentaram distribuição normal foram submetidos também ao teste Levene de homogeneidade das variâncias. Após isso foram submetidos ao Teste $t$ de médias emparelhadas. Os dados que não apresentaram distribuição normal foram submetidos ao teste não paramétrico de Wilcoxon. Alguns dados ao serem submetidos ao teste de variância não apresentaram Sig. maior ou igual a 0,05, não sendo possível prosseguir com o Teste $\mathrm{t}$, sendo submetidos então ao teste não paramétrico de Wilcoxon. Para a obtenção do Ranks todos passaram pelo teste de Wilcoxon.

Foi comparado os períodos de 20 meses anteriores e posteriores à Copa do Mundo, 3 meses anteriores e posteriores e o período da Copa comparado aos dois meses anteriores e posteriores para o volume de vendas no comércio varejista, receita de vendas no comércio varejista, receita de serviços e produção industrial. Todos esses períodos e variáveis foram estudados para os estados sede da Copa do Mundo e os estados que não foram sede dos jogos.

A primeira análise é do setor do comércio através do volume de vendas tendo como amostra os 12 estados brasileiros que foram sede dos jogos da Copa do Mundo de Futebol 2014 conforme Tabela 1. Todas as observações foram normais, apresentando Sig. > 0,05 para o teste de Shapiro-Wilk e apresentaram as variâncias homogênias, conforme Sig. > 0,05, para o teste de Levene. Observando o teste t de médias emparelhadas pode-se verificar que para os 20 meses anteriores e posteriores à Copa, 3 meses anteriores e 3 meses posteriores à copa e o período de realização daCopa do Mundo, comparado com os dois meses anteriores e posteriores o Sig. Foi $<0,05$ onde rejeita-se a hipótese nula, concluindo que ocorreram diferenças significativas no volume de vendas no comércio varejista, antes e depois, nesses períodos.

Com base nos Ranks que o teste Wilcoxon forneceu é possível concluir que, para todos os 12 estados sedes da Copa, a média do volume de vendas no 
comércio varejista no período de 20 meses anteriores Copa do Mundo foi maior que o volume de vendas posterior à Copa do Mundo. Analisando o período imediato de 3 meses, a média do volume de vendas depois da Copa foi maior do que o período de 3 meses anteriores para 11 estados.

Para a grande maioria dos estados, no período da Copa do Mundo, o volume de vendas do comércio varejista foi menor que os dois meses anteriores. Nos dois meses depois da Copa o volume de vendas do comércio varejista também foi maior do que no período do evento. Considerando os testes, há evidencias que durante o evento esportivo o volume de vendas do comércio varejista teve uma queda.

Tabela 1

Volume de Vendas no Comércio Varejista: Estados SEDE Copa do Mundo

\begin{tabular}{|c|c|c|c|c|c|c|c|}
\hline \multirow{2}{*}{\multicolumn{2}{|c|}{ Períodos }} & \multicolumn{2}{|c|}{ Shapiro-Wilk } & \multicolumn{2}{|c|}{ Levene } & \multicolumn{2}{|c|}{ Teste de Média } \\
\hline & & Estatística & Sig. & Estatística & Sig. & Estatística & Sig. \\
\hline 20 meses & $\begin{array}{l}\text { Antes } \\
\text { Depois }\end{array}$ & $\begin{array}{l}0,952 \\
0,958\end{array}$ & $\begin{array}{l}0,672 \\
0,749\end{array}$ & 0,012 & 0,914 & Teste t: 8,357 & 0,000 \\
\hline 3 meses & $\begin{array}{l}\text { Antes } \\
\text { Depois }\end{array}$ & $\begin{array}{l}0,971 \\
0,967\end{array}$ & $\begin{array}{l}0,925 \\
0,876\end{array}$ & 0,133 & 0,719 & Teste t: $-5,018$ & 0,000 \\
\hline dois meses & $\begin{array}{l}\text { Antes } \\
\text { Copa }\end{array}$ & $\begin{array}{l}0,973 \\
0,931\end{array}$ & $\begin{array}{l}0,944 \\
0,395\end{array}$ & 0,016 & 0,902 & Teste t: 5,724 & 0,004 \\
\hline dois meses & $\begin{array}{l}\text { Copa } \\
\text { Depois }\end{array}$ & $\begin{array}{l}0,932 \\
0,979\end{array}$ & $\begin{array}{l}0,399 \\
0,978\end{array}$ & 0,080 & 0,780 & Teste t: $-9,981$ & 0,000 \\
\hline
\end{tabular}

Fonte: Elaborado pelos autores.

Considerando a Tabela 2, todas as observações apresentaram normalidade e homogeneidade das variâncias, pois apresentaram Sig. > 0,05 sendo possível utilizar o teste $\mathrm{t}$ para comparar as médias emparelhadas. As médias da receita nominal de vendas em todos os períodos estudados também apresentaram Sig. < 0,05, assim rejeita-se $H_{0}$, concluindo que existem diferenças estatisticamente significativas. Conforme os Ranks extraídos a maioria dos estados que foram sede da copa apresentaram volume de vendas maior depois da copa, inclusive para o período imediato de 3 meses. Durante a Copa a receita nominal foi menor, tanto comparando os dois meses anteriores quando posteriores ao evento para os 12 estados. 
Tabela 2

Receita Nominal de Vendas no Comércio Varejista: Estados SEDE Copa do Mundo

\begin{tabular}{|c|c|c|c|c|c|c|c|}
\hline \multicolumn{2}{|c|}{ Períodos } & \multicolumn{2}{|c|}{ Shapiro-Wilk } & \multicolumn{2}{|c|}{ Levene } & \multicolumn{2}{|c|}{ Teste de Média } \\
\hline & & Estatística & Sig. & Estatística & Sig. & Estatística & Sig. \\
\hline 20 meses & $\begin{array}{l}\text { Antes } \\
\text { Depois }\end{array}$ & $\begin{array}{l}0,880 \\
0,949 \\
\end{array}$ & $\begin{array}{l}0,089 \\
0,627\end{array}$ & 0,966 & 0,336 & Teste t: $-4,301$ & 0,001 \\
\hline 3 meses & $\begin{array}{l}\text { Antes } \\
\text { Depois }\end{array}$ & $\begin{array}{l}0,914 \\
0,919 \\
\end{array}$ & $\begin{array}{l}0,239 \\
0,276\end{array}$ & 0,318 & 0,579 & Teste t: $-6,434$ & 0,000 \\
\hline dois meses & $\begin{array}{l}\text { Antes } \\
\text { Copa }\end{array}$ & $\begin{array}{l}0,915 \\
0,960\end{array}$ & $\begin{array}{l}0,244 \\
0,784\end{array}$ & 0,006 & 0,938 & Teste t: 9,463 & 0,000 \\
\hline dois meses & $\begin{array}{l}\text { Copa } \\
\text { Depois }\end{array}$ & $\begin{array}{l}0,960 \\
0,927\end{array}$ & $\begin{array}{l}0,784 \\
0,351\end{array}$ & 0,129 & 0,723 & Teste $\mathrm{t}:-10,780$ & 0,000 \\
\hline
\end{tabular}

Fonte: Elaborado pelos autores.

Analisando a Tabela 3, apenas as médias dos dois meses da realização da copa e depois apresentaram normalidade e homogeneidade das variâncias, pois Sig. > 0,05 sendo utilizado teste t de médias emparelhadas, os demais resultados não apresentaram normalidade sendo submetidos ao teste de Wilcoxon. A receita de serviços apresentou Sig. $<0,05$ apenas no período de 20 meses, ou seja, rejeita-se a hipótese nula, concluindo que houve diferenças na receita de serviços comparando os 20 meses anteriores e posteriores à Copa. Nos demais períodos ocorreram alterações, porém não foram significativas. Uma análise mais aprofundada nos dados nos infere que nos 20 meses posteriores à Copa do Mundo a receita de serviços foi maior que no mesmo período anterior ao evento para todos os estados.

\section{Tabela 3}

Receita Nominal de Serviços: Estados SEDE Copa do Mundo

\begin{tabular}{|c|c|c|c|c|c|c|c|}
\hline \multirow{2}{*}{\multicolumn{2}{|c|}{ Períodos }} & \multicolumn{2}{|c|}{ Shapiro-Wilk } & \multicolumn{2}{|c|}{ Levene } & \multicolumn{2}{|c|}{ Teste de Média } \\
\hline & & Estatística & Sig. & Estatística & Sig. & Estatística & Sig. \\
\hline 20 meses & $\begin{array}{l}\text { Antes } \\
\text { Depois }\end{array}$ & $\begin{array}{l}0,861 \\
0,826\end{array}$ & $\begin{array}{l}0,050 \\
0,019\end{array}$ & & & Wilcoxon: $-3,059$ & 0,002 \\
\hline 3 meses & $\begin{array}{l}\text { Antes } \\
\text { Depois }\end{array}$ & $\begin{array}{l}0,787 \\
0,922\end{array}$ & $\begin{array}{l}0,007 \\
0,299\end{array}$ & & & Wilcoxon: -1,883 & 0,060 \\
\hline dois meses & $\begin{array}{l}\text { Antes } \\
\text { Copa }\end{array}$ & $\begin{array}{l}0,840 \\
0,900\end{array}$ & $\begin{array}{l}0,028 \\
0,158\end{array}$ & & & Wilcoxon: $-0,039$ & 0,969 \\
\hline dois meses & $\begin{array}{l}\text { Copa } \\
\text { Depois }\end{array}$ & $\begin{array}{l}0,900 \\
0,940\end{array}$ & $\begin{array}{l}0,158 \\
0,497\end{array}$ & 0,035 & 0,854 & Teste $\mathrm{t}:-1,635$ & 0,130 \\
\hline
\end{tabular}

Fonte: Elaborado pelos autores.

Conforme Tabela 4 todas as médias apresentaram normalidade pois o teste de Shapiro-Wilk apresentou Sig. >0,05, ao serem submetidos ao teste de Levene para verificar a homogeneidade das variâncias o período da copa e dois meses posteriores apresentou Sig. $<0,05$ sendo utilizado o teste de Wilcoxon para comparar 
essas médias desse período. Os demais foram submetidos ao teste t. Apenas na comparação dos períodos de 20 meses anteriores e posteriores a copa ocorreram diferenças estatisticamente significativas na produção industrial, pois nesse período Sig. <0,05. Nos 20 meses anteriores a Copa do Mundo a produção industrial se mostrou maior do que nos 20 meses depois do evento para grande parte dos estados.

\section{Tabela 4}

Produção Industrial: Estados SEDE Copa do Mundo

\begin{tabular}{|c|c|c|c|c|c|c|c|}
\hline \multicolumn{2}{|c|}{ Períodos } & \multicolumn{2}{|c|}{ Shapiro-Wilk } & \multicolumn{2}{|c|}{ Levene } & \multicolumn{2}{|c|}{ Teste de Média } \\
\hline & & Estatística & Sig. & Estatística & Sig. & Estatística & Sig. \\
\hline 20 meses & $\begin{array}{l}\text { Antes } \\
\text { Depois }\end{array}$ & $\begin{array}{l}0,944 \\
0,943\end{array}$ & $\begin{array}{l}0,604 \\
0,585\end{array}$ & 1,139 & 0,300 & Teste t: 4,148 & 0,002 \\
\hline 3 meses & $\begin{array}{l}\text { Antes } \\
\text { Depois }\end{array}$ & $\begin{array}{c}0,918 \\
0,85\end{array}$ & $\begin{array}{l}0,342 \\
0,059\end{array}$ & 1,493 & 0,238 & Teste t: 0,140 & 0,892 \\
\hline dois meses & $\begin{array}{l}\text { Antes } \\
\text { Copa }\end{array}$ & $\begin{array}{l}0,974 \\
0,978\end{array}$ & $\begin{array}{l}0,924 \\
0,952\end{array}$ & 0,638 & 0,435 & Teste t: 1,550 & 0,155 \\
\hline dois meses & $\begin{array}{l}\text { Copa } \\
\text { Depois }\end{array}$ & $\begin{array}{l}0,978 \\
0,885\end{array}$ & $\begin{array}{l}0,952 \\
0,147\end{array}$ & 4,882 & 0,040 & Wilcoxon: -1,784 & 0,074 \\
\hline
\end{tabular}

Fonte: Elaborado pelos autores.

A partir de agora a análise será dos estados que não foram sede dos jogos da Copa do Mundo 2014.

Conforme Tabela 5 todas as médias apresentaram normalidade e homogeneidade das variâncias pois Sig. >0,05 para ambos os testes de ShapiroWilk e Levene respectivamente, podendo ser analisadas as médias com o teste t. Conforme teste o volume de vendas apenas para o período de dois meses anteriores comparado ao período de dois meses depois da Copa apresentou Sig. > 0,05 , ou seja, foi praticamente igual nesse período. Nos demais períodos as diferenças foram estatisticamente significativas (Sig. <0,05).

Nos 20 meses antes da Copa o volume de vendas foi maior que o mesmo período posterior. Nos 3 meses antes da Copa a situação muda, no período posterior é maior que no anterior ao evento para a maioria dos estados. O período de junho e julho apresentou volume de vendas no comércio menor que dois meses anteriores e posteriores. 
Tabela 5

Volume de Vendas no Comércio Varejista: Estados SEM Copa do Mundo

\begin{tabular}{|c|c|c|c|c|c|c|c|}
\hline \multirow{2}{*}{\multicolumn{2}{|c|}{ Períodos }} & \multicolumn{2}{|c|}{ Shapiro-Wilk } & \multicolumn{2}{|c|}{ Levene } & \multicolumn{2}{|c|}{ Teste de Média } \\
\hline & & Estatística & Sig. & Estatística & Sig. & Estatística & Sig. \\
\hline 20 meses & $\begin{array}{l}\text { Antes } \\
\text { Depois }\end{array}$ & $\begin{array}{l}0,910 \\
0,911\end{array}$ & $\begin{array}{l}0,138 \\
0,142\end{array}$ & 1,336 & 0,258 & Teste t: 4,581 & 0,000 \\
\hline 3 meses & $\begin{array}{l}\text { Antes } \\
\text { Depois }\end{array}$ & $\begin{array}{l}0,941 \\
0,940\end{array}$ & $\begin{array}{l}0,401 \\
0,387\end{array}$ & 0,932 & 0,343 & Teste t: $-4,887$ & 0,000 \\
\hline dois meses & $\begin{array}{l}\text { Antes } \\
\text { Copa }\end{array}$ & $\begin{array}{l}0,899 \\
0,949\end{array}$ & $\begin{array}{l}0,091 \\
0,509\end{array}$ & 1,028 & 0,319 & Teste t: 1,152 & 0,269 \\
\hline dois meses & $\begin{array}{l}\text { Copa } \\
\text { Depois }\end{array}$ & $\begin{array}{l}0,949 \\
0,944\end{array}$ & $\begin{array}{l}0,509 \\
0,432\end{array}$ & 0,059 & 0,810 & Teste t: $-2,787$ & 0,015 \\
\hline
\end{tabular}

Fonte: Elaborado pelos autores.

Todas as médias apresentaram normalidade e homogeneidade das variâncias de acordo com os testes Shapiro-Wilk e Levene respectivamente, como nos mostra a Tabela 6, pois Sig. >0,05 para ambos os testes podendo assim ser analisadas as médias com o teste $\mathrm{t}$. A receita nominal de vendas não apresentou diferenças estatisticamente significativas apenas para o período de dois meses anteriores, comparado aos dois meses da Copa do Mundo onde Sig. >0,05. A maioria dos estados apresenta receita nominal de vendas menores durante o evento. Os Ranks do teste de Wilcoxon inferem que nos 20 meses e 3 meses depois do evento a receita nominal foi maior que o mesmo período anterior. Os indicadores apresentaram diferenças estatisticamente maiores depois da Copa comparados aos dois meses do evento para praticamente todos os estados.

\section{Tabela 6}

Receita Nominal de Vendas no Comércio Varejista: Estados SEM Copa do Mundo

\begin{tabular}{|c|c|c|c|c|c|c|c|}
\hline \multicolumn{2}{|c|}{ Períodos } & \multicolumn{2}{|c|}{ Shapiro-Wilk } & \multicolumn{2}{|c|}{ Levene } & \multicolumn{2}{|c|}{ Teste de Média } \\
\hline & & Estatística & Sig. & Estatística & Sig. & Estatística & Sig. \\
\hline 20 meses & $\begin{array}{l}\text { Antes } \\
\text { Depois }\end{array}$ & $\begin{array}{l}0,913 \\
0,911\end{array}$ & $\begin{array}{l}0,151 \\
0,140\end{array}$ & 2,043 & 0,164 & Teste t: $-2,782$ & 0,015 \\
\hline 3 meses & $\begin{array}{l}\text { Antes } \\
\text { Depois }\end{array}$ & $\begin{array}{l}0,914 \\
0,937\end{array}$ & $\begin{array}{l}0,154 \\
0,349\end{array}$ & 0,914 & 0,347 & Teste t: $-5,967$ & 0,000 \\
\hline dois meses & $\begin{array}{l}\text { Antes } \\
\text { Copa }\end{array}$ & $\begin{array}{l}0,940 \\
0,942\end{array}$ & $\begin{array}{l}0,382 \\
0,408\end{array}$ & 0,497 & 0,487 & Teste t: 2,022 & 0,063 \\
\hline dois meses & $\begin{array}{l}\text { Copa } \\
\text { Depois }\end{array}$ & $\begin{array}{l}0,942 \\
0,948\end{array}$ & $\begin{array}{l}0,408 \\
0,494\end{array}$ & 0,016 & 0,902 & Teste t: $-3,892$ & 0,002 \\
\hline
\end{tabular}

Fonte: Elaborado pelos autores.

De acordo com a Tabela 7 todas as médias apresentaram Sig. > 0,05 no teste de Shapiro-Wilk, sendo consideradas normais. Ao serem submetidas ao teste de Levene, o período de 20 meses antes e depois da Copa não apresentou homogeneidade das variâncias, este apenas sendo submetido ao teste de Wilcoxon. 
Os demais períodos apresentaram homogeneidade das variâncias e foram submetidos ao teste t de médias. Para os estados que não foram sede da Copa do Mundo a receita nominal de serviços apresentou diferenças estatisticamente significativas para todos os períodos estudados, pois, Sig. $<0,05$. Nos 20 meses e nos 3 meses depois da Copa a maioria dos estados tiveram indicadores maiores que o mesmo período anterior ao evento. Durante a Copa do Mundo a receita nominal de serviços foi menor que os dois meses anteriores e posteriores.

\section{Tabela 7}

Receita Nominal de Serviços: Estados SEM Copa do Mundo

\begin{tabular}{|c|c|c|c|c|c|c|c|}
\hline \multirow{2}{*}{\multicolumn{2}{|c|}{ Períodos }} & \multicolumn{2}{|c|}{ Shapiro-Wilk } & \multicolumn{2}{|c|}{ Levene } & \multicolumn{2}{|c|}{ Teste de Média } \\
\hline & & Estatística & Sig. & Estatística & Sig. & Estatística & Sig. \\
\hline 20 meses & $\begin{array}{l}\text { Antes } \\
\text { Depois }\end{array}$ & $\begin{array}{l}0,885 \\
0,934\end{array}$ & $\begin{array}{l}0,057 \\
0,311\end{array}$ & 8,174 & 0,008 & Wilcoxon: $-2,471$ & 0,001 \\
\hline 3 meses & $\begin{array}{l}\text { Antes } \\
\text { Depois }\end{array}$ & $\begin{array}{c}0,898 \\
0,89\end{array}$ & $\begin{array}{l}0,089 \\
0,066\end{array}$ & 0,839 & 0,368 & Teste $\mathrm{t}:-2,820$ & 0,014 \\
\hline dois meses & $\begin{array}{l}\text { Antes } \\
\text { Copa }\end{array}$ & $\begin{array}{l}0,914 \\
0,937\end{array}$ & $\begin{array}{l}0,155 \\
0,342\end{array}$ & 0,285 & 0,597 & Teste t: 2,221 & 0,043 \\
\hline dois meses & $\begin{array}{l}\text { Copa } \\
\text { Depois }\end{array}$ & $\begin{array}{l}0,937 \\
0,915\end{array}$ & $\begin{array}{l}0,342 \\
0,162\end{array}$ & 0,086 & 0,771 & Teste t: $-4,530$ & 0,000 \\
\hline
\end{tabular}

Fonte: Elaborado pelos autores.

Todas as médias ao serem submetidas ao teste de Shapiro-Wilk e Levene apresentaram normalidade e homogeneidade nas variâncias respectivamente conforme Tabela 8, pois Sig.>0,05. Em relação ao teste t, os estados que não foram sede da Copa do Mundo e que possuem os dados disponíveis não apresentaram diferenças estatisticamente significantes na produção industrial, pois, Sig.>0,05, concluindo-se essa variável foi igual antes e depois da Copa para todos os períodos estudados.

Tabela 8

Produção Industrial: Estados SEM Copa do Mundo

\begin{tabular}{|c|c|c|c|c|c|c|c|}
\hline \multicolumn{2}{|c|}{ Períodos } & \multicolumn{2}{|c|}{ Shapiro-Wilk } & \multicolumn{2}{|c|}{ Levene } & \multicolumn{2}{|c|}{ Teste de Média } \\
\hline & & Estatística & Sig. & Estatística & Sig. & Estatística & Sig. \\
\hline 20 meses & $\begin{array}{l}\text { Antes } \\
\text { Depois }\end{array}$ & $\begin{array}{l}0,987 \\
0,897 \\
\end{array}$ & $\begin{array}{l}0,942 \\
0,417 \\
\end{array}$ & 2,074 & 0,200 & Teste t: $-0,868$ & 0,449 \\
\hline 3 meses & $\begin{array}{l}\text { Antes } \\
\text { Depois }\end{array}$ & $\begin{array}{l}0,879 \\
0,825 \\
\end{array}$ & $\begin{array}{l}0,335 \\
0,154 \\
\end{array}$ & 0,565 & 0,481 & Teste t: $-1,496$ & 0,232 \\
\hline dois meses & $\begin{array}{l}\text { Antes } \\
\text { Copa }\end{array}$ & $\begin{array}{c}0,87 \\
0,994\end{array}$ & $\begin{array}{l}0,299 \\
0,978 \\
\end{array}$ & 0,152 & 0,710 & Teste t: $-0,058$ & 0,957 \\
\hline dois meses & $\begin{array}{l}\text { Copa } \\
\text { Depois }\end{array}$ & $\begin{array}{l}0,994 \\
0,881 \\
\end{array}$ & $\begin{array}{l}0,978 \\
0,343 \\
\end{array}$ & 0,457 & 0,524 & Teste t: $-2,566$ & 0,083 \\
\hline
\end{tabular}

Fonte: Elaborado pelos autores. 
Os resultados dos testes de mostram adversos principalmente indicando que no período da Copa do Mundo a receita de vendas do comércio e serviços foi menor que os demais períodos. É preciso lembrar que o período analisado posterior a Copa compreende de agosto de 2014 até março de 2016, período em que a crise política e econômica brasileira estava consolidada não podendo atribuir o desempenho das variáveis apenas ao evento em estudo. O consumo das famílias vem caindo desde 2014 no Brasil, elas estão mais endividadas além das menores condições de crédito devido ao aumento das taxas de juros (Instituto de Pesquisa Econômica Aplicada, 2014). A inflação vem superando a marca de $10 \%$ a mais de 10 anos e ocorre uma disseminada deterioração no balanço de pagamento brasileiro (Instituto de Pesquisa Econômica Aplicada, 2015).

O problema não se encontra apenas na demanda, a produtividade do trabalho se encontra estagnada há algum tempo o que implica problemas de custos de produção e rentabilidade, principalmente no setor industrial. Embora em 2014 teve uma quantidade menor de dias uteis em função da Copa do Mundo, a produção recuou ao patamar de 5 anos atrás sugerindo problemas estruturais. O mau desempenho também das exportações reflete os problemas competitivos enfrentados pela indústria brasileira (IPEA, 2014).

O setor de serviços que é o responsável pela grande maioria dos novos empregos gerados também está sentindo a crise econômica apresentando crescimento nos três trimestres de 2014 de apenas $0,9 \%$, o pior em mais de 10 anos (IPEA, 2014).

A situação tornou-se ainda mais dificil com a eclosão de uma crise política, o Ministério Público Federal investiga casos de corrupção com a operação Lava Jato, população inicia ondaa de protestos e surgem rumores de processo de impeachment da presidenta Dilma Roussef.

\section{Considerações Finais}

As atividades comerciais, de serviços e industriais são a base de uma economia, gerando e distribuindo de renda, empregos, além de serem setores que se interligam. 
O objetivo do trabalho foi verificar se houve impacto estatisticamente significativo no volume de vendas do comércio varejista, receita nominal de vendas, receita de serviços e produção industrial durante a realização da Copa do Mundo de Futebol 2014, para os estados brasileiros que foram sede do evento e os que não foram. Foi analisado também se essas variáveis foram impactadas pela Copa do Mundo nos 20 meses e 3 meses anteriores à Copa, comparado com o mesmo período posterior.

Respondendo ao objetivo, pode-se concluir que o volume de vendas no comércio varejista, para os estados sede e os estados sem jogos da copa, apresentaram diferenças estatisticamente maiores nos 20 meses antes da copa comparados aos 20 meses depois. Ao contrário, o volume de vendas foi estatisticamente maior nos três meses depois do evento comparado com os 3 meses anteriores. Durante a Copa ele foi menor, comparado aos dois meses anteriores e posteriores.

A receita nominal de vendas do comércio, tanto para os estados sede da Copa do Mundo e quanto para os estados sem jogos da Copa, foi menor antes da Copa na comparação dos períodos de 20 meses e 3 meses. Durante a realização do evento a receita nominal de vendas foi menor do que no período de dois meses anteriores e posteriores. Apenas para os estados que não foram sede do evento a mudança não foi significativa, comparando o período posterior com o evento.

A receita de serviços para os estados sede da Copa do Mundo de 2014 apresentou diferenças significativas apenas na comparação com os 20 meses anteriores e posteriores ao evento, onde nos 20 meses anteriores foram menores. Os períodos de 20 meses e 3 meses anteriores à Copa apresentaram receita de serviços menor que o mesmo período anterior, para os estados que não foram sede do evento. A receita de serviços foi menor durante o evento, comparando com os dois meses anteriores e posteriores.

Os resultados encontrados para o comércio e serviços embora no período de dois meses da Copa não foram positivos, tiveram alterações anteriores ou posteriores ao evento corroborrando as suposições de Domingues et al. (2011) ondem citavam que mega-eventos como a Copa trariam beneficios difíceis de estimar, mas que estimulariam os negócios domésticos como restaurantes, hotéis e outros negócios. O impacto dos investimentos do evento sobre o PIB em cada 
estado seria influenciado tanto pelo tamanho dos investimentos em cada estado como pela estrutura produtiva de cada região e sua inserção na economia brasileira. Investimento na melhoria da infraestrutura urbana das cidades é o que efetivamente gera impacto de longo prazo da economia.

A produção industrial não apresentou diferenças significativas nos períodos estudados para os estados que não foram sede dos jogos da Copa do Mundo. Para os que foram sede, ocorreram diferenças significativas apenas nos 20 meses anteriores ao evento, onde foram maiores que o mesmo período pós Copa. Esse resultado pode ter se dado em virtude das obras dos estádios e infraestrutura das cidades. Glória Junior (2015) cita a criação de aeroportos, construção de estádios e reformas e obras de infraestrutura urbana realizados pela iniciativa pública e investimentos da iniciativa privada como exemplo a criação de um hotel. Domingues et al. (2011) também citam a iniciativa privada realizando investimentos para o evento. Aponta também que investimentos privados nos estadios gera aumento do PIB e emprego apenas na fase de construção.

Os resultados da pesquisa refletem resultados diversos, mas pode-se concluir que não houveram grandes diferenças na receita e volume de vendas do comércio varejista, receita de serviços e produção industrial para os estados que foram sede da Copa e os que não foram divergindo de Domingues et al. (2011) que encontraram em seus estudos que os impactos nos estados sede do evento seriam maiores do que nos estados que não tiveram jogos.

Uma limitação do estudo é o que os indicadores do IBGE são coletados apenas para empresas com mais de 20 funcionários, as empresas menores não estão na pesquisa e podem ter apresentado resultados expressivos durante a Copa do Mundo.

Não se pode atribuir às diferenças na receita e volume do comércio, receita de serviços e produção industrial, verificadas nos períodos estudados, apenas à realização da Copa do Mundo, muitos outros fatores podem ter contribuído para as alterações positivas e negativas. É importante lembrar que o período posterior a Copa compreende de agosto de 2014 até março de 2016, período em que a crise política e econômica brasileira estava consolidada, onde iniciava-se a operação Lava Jato pelo Ministério Público Federal, processo de impeachment da Presidenta Dilma Roussef além de um período de juros altíssimos no Brasil, queda dos investimentos externos, podendo ser fatores favoráveis à alterações desses 
indicadores. Descobrir, descrever e aprofundar a análise desses fatores serve de sugestão para trabalhos futuros.

\section{Referências}

Bayar, O. Schaur G. (2014). The Impact of Visibility on Trade: Evidence from the World Cup. Review of International Economics, 22(4), 759-782. Recuperado em 20 de junho, 2016 , http://onlinelibrary.wiley.com/doi/10.1111/roie.12125/abstract;jsessionid=BE2AB6532 1BAEC12B2D3A5AE1280F45C.f04t03?userlsAuthenticated=false\&deniedAccessCu stomisedMessage.

Carvalho, M. S. de. (2004). Absorção de mão-de-obra no setor de serviços brasileiro dos anos 90. Dissertação de Mestrado. Instituto de Economia da UNICAMP, Campinas, São Paulo, SP, Brasil. Disponível: http://www.bibliotecadigital.unicamp.br/document/?code=vtls000339219.

Cleps, G. D. G. (2004). O comércio e a cidade: novas territorialidades urbanas. Revista Sociedade \& Natureza, 16(30), 117-132. Recuperado em 15 de junho, 2016, de http://www.seer.ufu.br/index.php/sociedadenatureza/article/viewFile/9183/5648.

Deitos, M. L. M. S. (2012). O Processo de Incorporação de Tecnologia na Indústria Brasileira: dos primórdios da industrialização à abertura comercial nos anos 1990 . Revista Gestão e Tecnologia, 12, 04-25. Recuperado em 28 de março, 2017, de https://revistagt.fpl.edu.br/get/article/view/302/347.

Diniz, L. H. F. (2007). Distribuição e funcionalidades espaciais do setor terciário no Brasil 1991-2000. Dissertação de Mestrado.Universidade Federal de Minas Gerais-UFMG, Belo Horizonte, MG, Brasil. Disponível: http://www.bibliotecadigital.ufmg.br/dspace/handle/1843/MPBB-7WENPG.

Domingues, E. P., Betarelli Junior, A. A. \& Magalhães, A. S. (2011). Quanto vale o show? Impactos econômicos dos investimentos da Copa do Mundo 2014 no Brasil. Estudos Econômicos, 41(2), 409-439. Recuperado em 16 de junho, 2016, de http://www.scielo.br/pdf/ee/v41n2/a08v41n2.

Fávero, L. P. Befiore, P. Silva, F. L. da \& Chan, B. L. (2009). Análise de dados: modelagem multivariada para tomada de decisões. Rio de Janeiro: Campus.

Freire, A. L. O. (2010). O desenvolvimento do comércio e a produção do espaço urbano. GeoTextos, 6(2). Recuperado em 15 de junho, 2016, de http://www.portalseer.ufba.br/index.php/geotextos/about/contact.

Gadelha, C. A. G. (2006). Desenvolvimento, complexo industrial da saúde e política industrial. Revista de saúde pública, 40(edição especial), 11-23. Recuperado em 15 de junho, 2016, de http://www.scielosp.org/pdf/rsp/v40nspe/30617.pdf. 
Glória Junior, I. (2015). A Copa do Mundo de 2014 na perspectiva da tríplice restrição: uma Copa sem gols. Podium Sport, Leisure and Tourism Review, 4(2), 17-28. Recuperado em 16 de junho, 2016, de https://dialnet.unirioja.es/servlet/articulo?codigo $=5190973$.

Gremand, A. P.; Vasconcellos, M. A. S. \& Toneto Junior, R. (2007). Economia Brasileira Contemporânea. São Paulo: Atlas.

Instituto de Pesquisa Econômica Aplicada. (2014). Carta de Conjuntura 25. Recuperado em 29 março, 2017, de http://www.ipea.gov.br/portal/images/stories/PDFs/conjuntura/150318_cc_dez2014_fi nal1.pdf.

Instituto de Pesquisa Econômica Aplicada. (2015). Carta de Conjuntura 29. Recuperado em 29 março, 2017, de http://www.ipea.gov.br/portal/images/stories/PDFs/conjuntura/160318_carta_de_conj untura_29.pdf.

Krugman, P. \& Wells, R. (2007). Introdução à economia. Rio de Janeiro: Elsevier.

Kureski, R. \& Delgado, P. R. (2012). A importância do setor de serviços no Estado do Paraná. Revista Paranaense de Desenvolvimento-RPD, vol. 118, 139-158. Recuperado em 10 de junho, 2016, de http://www.ipardes.pr.gov.br/ojs/index.php/revistaparanaense/article/view/135/643.

Mariano, J. (2007). Marketing structure and the tendencies towards business activity. Iberoamerican Journal of Strategic Management (IJSM), 55-64. Recuperado em 13 de junho, 2016, www.revistaiberoamericana.org/ojs/index.php/ibero/article/view/14.

Mankiw, N. G. (2001). Introdução à economia: princípios de Micro e Macroeconomia (M. J. C. Monteiro Trad., 2a ed.). Rio de Janeiro: Elsevier.

Pace, T. H., Hardt, L. P. A. \& Figueiredo, F. de C. (2015). SPORTING MEGA-EVENTS AND TOURISM: Bibliometric Relationships in Academia. Business and Management Review, 4(12). Recuperado em 21 de junho, 2016, de http://www.businessjournalz.org/Brazil\%20Special\%20Edition/SI\%20May,\%202015/B MR(00118)-V4-N12-May-2015-SI-VII-03.pdf.

Paranhos Filho, M. (2007). Gestão da Produção Industrial.Curitiba: Ibpex. Recuperado em 28 de março de 2017, de https://books.google.com.br/books?hl=ptBR\&Ir=\&id=00tfS8k_FgMC\&oi=fnd\&pg=PA9\&dq=produ\%C3\%A7\%C3\%A30+industri al\&ots=mnSqnxr4FV \&sig=QcnT9od_EV1dWiVbW5roqU76apE\#v=onepage \&q=produ $\% \mathrm{C} 3 \% \mathrm{~A} 7 \% \mathrm{C} 3 \% \mathrm{~A} 30 \% 20$ industrial\&f$=$ false.

Passos, C. R. M. \& Nogami, O. (1998). Princípios de Economia. São Paulo: Pioneira.

Porto, L. P. \& Ceron, L. F. (2013). Brasil. Copa do Mundo 2014: análise dos impactos ambientais, econômicos e sociais. Revista Eletrônica do Curso de Direito da UFSM, 
vol. 8, 437-446. Recuperado em 16 de junho, 2016, de http://periodicos.ufsm.br/index.php/revistadireito/article/view/8346\#.V2MKW7srLIU.

Ribeiro, C. H. de V., Soares, A. J. G. \& Dacosta, L. P. (2014). Percepção sobre o legado dos megaeventos esportivos no Brasil: O caso da Copa do Mundo FIFA 2014 e os jogos olímpicos Rio 2016. Revista Brasileira de Ciências do Esporte, 36(2), 447-466. Recuperado em 15 de junho, 2016, de http://oldarchive.rbceonline.org.br/index.php/RBCE/article/view/1249.

Scandelai, A. L. de O. (2010). A precarização do trabalho: da revolução industrial ao neoliberalismo. Colloquium Humanarum, 7(1), 21-31. Recuperado em 10 de junho, 2016, de http://revistas.unoeste.br/revistas/ojs/index.php/ch/article/viewArticle/340.

Stiglitz, J. E. \& Walsh, C. E. (2003). Introdução à Microeconomia. (H. Hoffmann Trad., 3a ed.). Rio de Janeiro: Campus.

Suzigan, W. \& Furtado J. (2006). Política Industrial e Desenvolvimento. Revista de Economia Política, 26 (2), 163-185. Recuperado em 28 de março de 2017, de http://www.scielo.br/pdf/rep/v26n2/a01v26n2.

Ugarte, M. C. D. (2004). Homo motor, ciborgues e... aha! Pessoas-Da revolução industrial à revolução da informação. Dissertação de Mestrado. Faculdade de Educação Física da Unicamp, Campinas, SP, Brasil. Disponível em: http://www.bibliotecadigital.unicamp.br/document/?code=vtls000348673\&fd=y. 